\title{
Leitura na biblioteca escolar: desafios e possibilidades
}

\author{
Reading in school library: challenges and possibilities
}

Ana Claudia Costa de Aquino Teixeira*
Flavia Aninger de Barros Rocha**

Resumo: Um livro, um leitor, uma biblioteca. Um cenário propício e convidativo ao estímulo à leitura. Com o objetivo de socializar os resultados de uma intervenção pedagógica de leitura, intitulada "Tempo para o letramento literário: uma proposta de leitura na biblioteca escolar”, o presente trabalho descreve atividades desenvolvidas com estudantes do quinto ano do Ensino Fundamental I em uma escola pública municipal situada no município de Feira de Santana/Bahia que se configuram numa ação de mediação realizada no Mestrado Profissional em Letras (ProfLetras) da Universidade Estadual de Feira de Santana. Como procedimentos metodológicos foram utilizados: a) a leitura mediada (SOLÉ, 1998; BALDI, 2009) do livro “O menino e o tuim”, do escritor Rubem Braga (1986), cujo principal foco é garantir reflexão sobre o gênero crônica literária numa comparação com os contos clássicos; b) atividades organizadas em sequencia didática (DOLZ \& SCHNEWULY, 2004) que permitiram conhecer o perfil leitor e saber como as crianças de 10 a 12 constroem sentidos a partir da interação com o gênero selecionado e c) o empréstimo de livros do acervo da biblioteca escolar. Os resultados apontam que as/os estudantes estão em prontidão a tocar os livros de literatura da biblioteca escolar dando voz aos muitos saberes relacionados ao texto literário e ainda sinalizam que a formação do leitor literário está intimamente ligada às experiências de leitura do mediador. Esperamos que esse material contribua cada vez mais na formação do leitor literário, uma das metas mais desafiadoras para a escola.

Palavras chave: Leitura. Letramento. Literatura. Biblioteca escolar.

Abstract: A book, a reader, a library. A positive and inviting scenario to encourage reading. In order to socialize the results of an educational intervention in reading, entitled "Time for literary literacy: a reading of the proposal in the school library", this paper describes activities with $5^{\text {th }}$ grade students of a public Elementary school located in Feira de Santana, Bahia. These activities were part of a mediation action carried out in the Professional Master of Arts Program (ProfLetras) of the State University of Feira de Santana. The methodological procedures included: a) the mediated reading (SOLÉ, 1998; BALDI, 2009) of the book "The boy and the tuim" by Rubem Braga (1986), whose main focus is to ensure reflection on the literary chronicle genre in comparison to classic tales; b) activities organized in a didactic sequence (DOLZ \& SCHNEUWLY, 2004) that revealed the reader profile and showed how 10 to 12 -year-old children construct meanings from the interaction with the selected genre c) the loan of books from the school library collection. The results show that students are ready to touch the school library literature books. They also indicate that the formation of the literary reader is closely linked to the mediator reading experiences. We hope this material will contribute to the formation of the literary reader, one of the most challenging school goals.

Keywords: Reading. Literacy. Literature. School library.

\section{INTRODUÇÃO}

Sendo professora de uma unidade escolar da rede pública municipal de ensino de Feira de Santana - BA, desde o ano de 2012, é possível perceber como o tema da leitura permeia o discurso docente em praticamente todos os espaços da escola: nos corredores, no pátio, no portão, nas reuniões. Atrelado ao discurso da leitura,

\footnotetext{
* Mestranda do ProfLetras - Mestrado Profissional em Letras pela Universidade Estadual de Feira de Santana. anaccat@gmail.com

** Prof. Adjunta da Universidade Estadual de Feira de Santana. flavianinger@gmail.com.
} 
está associada a observação do desempenho das/dos estudantes em avaliações internas e externas que, no geral, é mediano (no nível da decodificação) ou insatisfatório (no nível do não saber ler). Buscando entender as possíveis causas da baixa proficiência em leitura, passei a observar como se davam os momentos de envolvimento/contato com a escrita.

As observações iniciais apontam que, apesar dos avanços nos estudos sobre a concepção de ensino de Língua Portuguesa pela via dos gêneros textuais a partir das orientações dos Parâmetros Nacionais Curriculares (PCN) publicados em 1998, há, ainda, muito o que ser difundido e implementado sobre práticas escolares que permitam o contato de meninas e meninos com o maior número possível de gêneros de texto.

O presente projeto, configurado numa pesquisa-ação, apresentado ao ProfLetras/Mestrado Profissional em Letras, tem como principal objetivo, ampliar as discussões sobre o tema da leitura e da escrita como práticas de participação social. Neste sentido, todos têm direito a tocar o livro e a ele atribuir sentidos e, de dizer sobre si e seu mundo por meio da produção de textos orais e escritos, práticas possíveis de serem realizadas na biblioteca escolar - potencial para a consolidação de múltiplos letramentos, dentre eles o letramento literário - espaço que faz parte do imaginário dos indivíduos.

Procurou-se neste projeto, ainda, refletir como se desenvolve uma sequencia didática que tem como principal foco a leitura em voz alta realizada na biblioteca escolar como recurso motivador para a formação do leitor e escritor e, qual o papel desta intervenção no ensino-aprendizagem de língua materna. O público selecionado foi uma turma de estudantes do $5^{\circ}$ Ano do Ensino Fundamental, como forma de refletir sobre as memórias de leitura construídas ao final do primeiro ciclo.

Além da leitura em voz alta, o acervo da biblioteca escolar, neste projeto, tem papel fundamental para a ampliação de experiências com a literatura, já que o empréstimo de obras aponta para um dado importantíssimo: o livro - de papel tem o seu lugar assegurado num mundo fortemente marcado pela escrita virtual.

\section{LEITURA NA ESCOLA E A FORMAÇÃO DO LEITOR}

Quando nos questionamos sobre como concebemos leitura e qual é a nossa percepção sobre ela, certamente afirmaremos que ler é importante pois estimula os estudos, amplia a visão de mundo e é uma prática que nos traz empoderamento social. Então por que ainda não conseguimos que todos os brasileiros desfrutem dessa experiência de vida tão marcante?

A proposta de ler na escola é uma das investidas mais desafiadoras a que esse espaço se impõe. De acordo com Jouve (2002), ler é uma atividade complexa para a qual o indivíduo terá que recorrer a diferentes funções cerebrais. A leitura é um ato de múltiplas facetas para aquele que a domina, tornando-o ainda mais atento ao seu entorno e, por esta razão é importante pensar o ato de ler como uma atividade planejada. Além disso, ler é uma atividade que transforma e impacta de uma vez por todas as formas de recepcionar e conceber o mundo, portanto, ensinar a ler em 
sociedades organizadas a partir da escrita, passa a ser uma das principais missões da escola.

Tomando os gêneros de texto como objeto de ensino/aprendizagem para a aprendizagem da leitura e, também, da escrita, a escola pode criar condições favoráveis para uma aprendizagem mais significativa, visto que, segundo Dolz \& Schnewuly (2004, p. 75) o gênero "pode ser considerado como megainstrumento que fornece suporte para a atividade nas situações de comunicação, e uma referência para os aprendizes". Nesse sentido, a escola precisa decidir e fazer escolhas didáticas levando em consideração que o gênero antes de ser aprendido deve ser concebido como gênero para se comunicar.

Sendo assim, as situações didáticas planejadas em torno de um gênero devem priorizar situações próximas a que já existem nas situações reais de interação a que os estudantes participam cotidianamente. Para possibilitar que o processo de leitura se consolide como um ato de interação entre o leitor e o texto, é necessário viabilizar práticas leitoras que promovam múltiplos letramentos a fim de que o ato de ler seja uma prática social e cultural.

A leitura em voz alta, tomada neste projeto como estratégia pedagógica, objetiva colaborar com o processo contínuo de letramento. O professor, como uma referência de leitura, pode mobilizar os leitores iniciantes possibilitando uma ampliação no que diz respeito às estratégias de leitura. Sobre isto, Solé (1998) orienta que a leitura deve ser tomada como objeto de conhecimento e como instrumento necessário para novas aprendizagens. Além de colaborar para a compreensão leitora, a leitura em voz alta pelo professor pode motivar os estudantes a ampliar seu repertório leitor, e neste sentido, a biblioteca escolar se apresenta como um espaço potencial para a consolidação desta ação.

Portanto, além de apresentar os livros aos alunos - lê-los para e com eles -, a biblioteca escolar e seu acervo passam a "pertencer" ao maior número de estudantes prontos a dar asas à imaginação, partilhar e conhecer realidades diversas, fortalecendo assim o vínculo com o escrito.

\section{BIBLIOTECA ESCOLAR E SUAS POSSIBILIDADES}

A história das bibliotecas é tão antiga que se confunde (grosso modo) com a história da própria humanidade. Fazer história é criar um material que serve de acervo a uma biblioteca que primeiramente é "virtual" - ideias guardadas na memória - e depois se difunde de forma materializada nas escritas encontradas atualmente em diversas bibliotecas espalhadas pelo mundo. Funari (2012, p.4) explica um pouco sobre isso:

$\mathrm{Na}$ verdade a Biblioteca de Alexandria não era do jeito como conhecemos as bibliotecas hoje. Não era um lugar para se guardar livros [...], o conhecimento era registrado em rolos [...] tinha, sim seu acervo, mas estava mais para um centro cultural. Os maiores intelectuais iam para lá trocar ideias, além de artistas e todos os interessados nas novidades. 
Portanto, a biblioteca deve ser concebida como espaço de construção de conhecimento por meio da interação de ideias e ideais. Um espaço para a consolidação de ações que impactam de alguma forma a sociedade e sua postura em relação ao mundo. Dessa forma, vista como um espaço de letramentos na escola, a biblioteca pode conter em si e viabilizar atividades que criem uma ponte entre o real e o imaginário, entre o real e o ideal através de práticas que envolvam os gêneros de texto para a produção oral e escrita.

A biblioteca, da instituição selecionada para a aplicação do projeto, no que se refere ao espaço físico, mobiliário e localização tem algumas peculiaridades. A biblioteca foi pensada após a escola ser construída, mais precisamente quando os livros do Programa Nacional Biblioteca da Escola (PNBE) chegaram à unidade escolar (a chegada dos livros do PNBE se deu a partir de 2002; a escola foi construída na década de 80).

Sendo assim, no projeto inicial de construção da unidade de ensino, não constava o espaço destinado à biblioteca escolar. A escolha desse espaço se deu por conta da urgência em acomodar as obras e, então, foi escolhida uma sala que estava vazia e fica no primeiro andar do prédio. O mobiliário da biblioteca é o mesmo das salas da Educação Infantil e é utilizado por todos os alunos de 2 anos ao $5^{\circ}$ ano; o espaço físico é pequeno abrigando não mais que 20 estudantes, já que são 5 pequenas mesas compostas de 4 cadeiras em cada uma delas (o projeto foi aplicado a 22 estudantes e a matrícula de alunos, geralmente, ultrapassa esses números).

É importante destacar que o PNBE contribuiu de forma decisiva, apesar de questões como as descritas acima, para a ampliação das possibilidades do acesso à leitura no espaço escolar desde o seu início em 1997, já que impulsiona práticas de ensino em torno da literatura, texto que agrega em si o real, o imaginário e o mágico.

Nessa perspectiva, no espaço da biblioteca escolar é possível promover momentos de escuta, de conversas e até de silêncio, mas nunca o silêncio ideológico e sim o silêncio físico que permite a reflexão das leituras. A biblioteca jamais pode ser concebida como o espaço "de horários vagos", de ações não planejadas, improvisadas, correndo o sério risco de passar de espaço de conhecimento para espaço de enfado e castigo. De acordo com Freire (1989) a compreensão crítica da biblioteca desenvolve a compreensão crítica da alfabetização e da leitura. Nesse sentido, Moraes (2013, p. 25) afirma:

\footnotetext{
Portanto, para que a alfabetização e a leitura sejam práticas fundadas em uma compreensão crítica, é imprescindível que a biblioteca seja concebida como espaço popular no qual a voz do educando, a fala do povo, a linguagem da comunidade e os saberes locais tenham vez [...].
}

No que se refere à proposta deste projeto, que objetiva, também, dinamizar e dar visibilidade ao espaço da biblioteca escolar, a leitura em voz alta se tornou uma ação promissora, visto que, a partir da atividade de leitura em voz alta da crônica O menino e o tuim (RUBEM BRAGA, 1986), a retirada de livros na biblioteca se tornou uma prática contínua permitindo aos estudantes o contato com variados gêneros e motivando-os a ler de forma significativa, pois ao final da leitura de cada 
livro os relatos orais sobre as leituras eram produzidos e desses relatos as crianças produziram o resumo escrito do livro favorito, gerando, assim, um cartaz intitulado "Histórias recomendadas", para estimular outros estudantes a ler.

Figura 1 - Resumo escrito do livro favorito lido na biblioteca durante o projeto

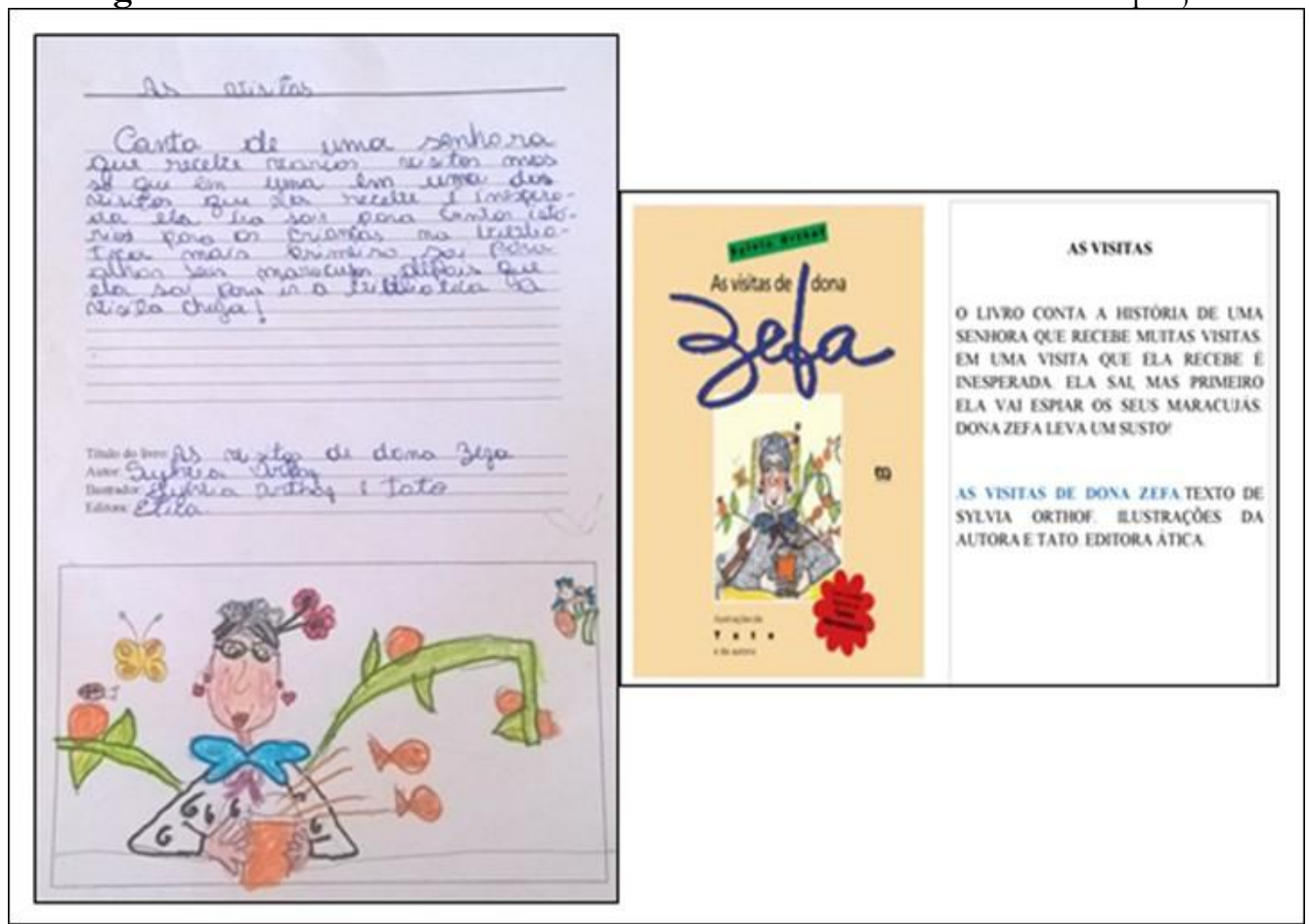

\section{UMA EXPERIÊNCIA EM CONSTRUÇÃO}

O projeto "Tempo para o letramento literário: uma proposta de leitura no espaço da biblioteca escolar" objetiva aproximar os estudantes do texto literário. Para a consolidação da ação, um questionário composto de 9 questões, foi aplicado com o propósito de levantar dados sobre o contato dos estudantes com a leitura e a biblioteca. As perguntas foram feitas levando em consideração o ciclo escolar em que as crianças se encontram, final do Ensino Fundamental I.

A partir da análise das respostas, foi possível organizar atividades numa sequência didática adaptada da proposta de Schneuwly \& Dolz (2004). Essas atividades permitiram conhecer o perfil leitor e saber como estudantes de 10 a 12 de uma turma de $5^{\circ}$ Ano do Ensino Fundamental I constroem sentidos a partir da interação com o gênero selecionado, crônica. Ainda, como parte das atividades empreendidas no projeto, o empréstimo na biblioteca escolar foi consolidado como uma condição favorável à ampliação do repertório de leitura.

Após, a apresentação do projeto à comunidade escolar, percebeu-se que na rotina da escola a visitação à biblioteca e o empréstimo de livros do seu acervo não se configuravam, ainda, como ações sistematizadas. Por esta razão o projeto se 
mostrou como um diferencial na rotina das crianças, trazendo novas expectativas e construções sobre o ato de ler a partir das ações desenvolvidas naquele espaço.

No primeiro contato com as crianças, por meio da aplicação do questionário semi-estruturado, foi possível perceber a euforia quando foram expostas as intenções do projeto relacionadas à leitura e escrita na biblioteca da escola. Abaixo, seguem algumas perguntas e respostas que permitiram construir uma sequência de atividades que desse conta do anseio das crianças: tocar e se encantar com os livros que estão dentro da biblioteca.

Figura 2-Questão 4/Questionário de sondagem

\begin{tabular}{|ll|}
\hline 4. Escreva o nome de uma história que você já leu. \\
João e o pé de feijão & Chapeuzinho vermelho \\
Turma da Mônica & Branca de neve \\
Diário de um banana & Os três porquinhos \\
Hora de tomar banho & Cinderela \\
A pequena Sereia & A bela e a fera \\
O mágico de Oz & Cachinhos Dourados \\
Maluquinho & A princesa e o sapo \\
O patinho feio & \\
\hline
\end{tabular}

Analisando a figura 1, percebemos que o conto de fadas e o conto fantástico constroem essa primeira memória de leitura das crianças e, com base no que sinaliza Vigotsky, é a partir do que eles já sabem sobre o que leem (conhecimentos prévios sobre leitura) e, levando em consideração a tipologia textual presente no gênero conto de fadas, que foi selecionado o gênero textual crônica literária também dentro do eixo NARRAR (DOLZ \& SHCNEWULY, 2004, p. 50), a fim de permitir que os estudantes a ampliem seu repertório para além do mágico.

Sobre o contato com a biblioteca, vejamos o que os estudantes sinalizam:

Gráfico 1 - Questão 5/Questionário de sondagem

5. Você costuma ir à biblioteca da sua escola?

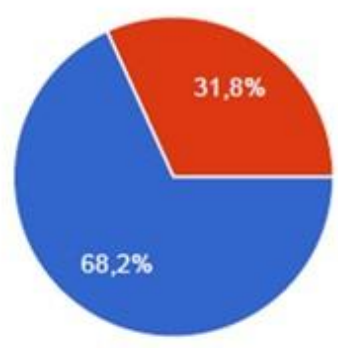

SIM $15 \quad 68.2 \%$

NÄO $\quad 7 \quad 31.8 \%$

É importante analisar a Figura 2 sob a hipótese de que essa turma pode ser composta de alunos oriundos de turmas e escolas diferentes, o que pode sinalizar 
que a biblioteca ainda não é uma realidade para todos os estudantes, objetivo perseguido por esta proposta de trabalho e que já foi consolidado através da intervenção. Dos vinte e dois estudantes que participam do projeto, todos estão inseridos na rotina semanal de visitação à biblioteca e empréstimos de obras literárias.

Ainda sobre o contato com a biblioteca escolar e os livros do seu acervo, a resposta apresentada à próxima pergunta confirma uma das hipóteses deste projeto que diz respeito ao afastamento entre os estudante e a literatura.

Gráfico 2-Questão 7/Questionário de sondagem

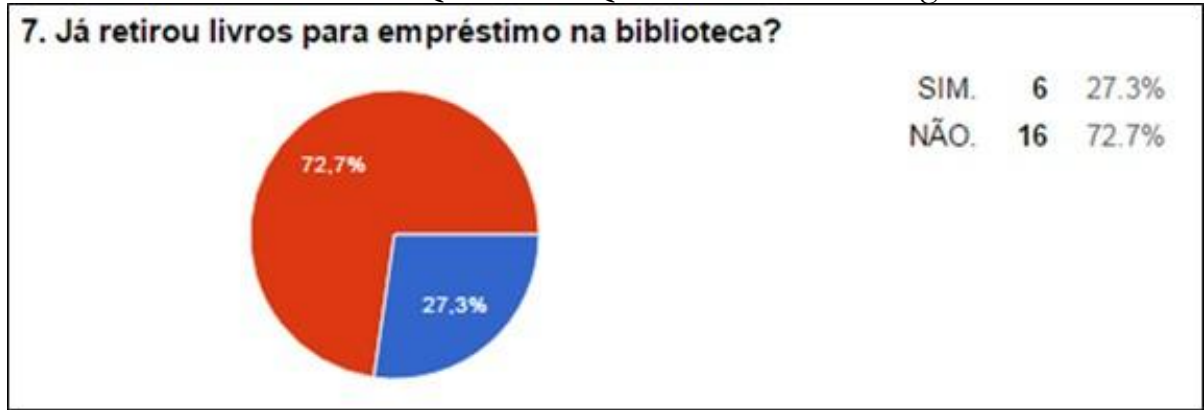

A análise das respostas aos questionários tem sinalizado que há uma necessidade urgente em colocar os estudantes em contato com a leitura por meio de ações que promovam os múltiplos letramentos, visando uma maior participação desses sujeitos em situações que exijam a leitura proficiente. É importante, ainda, entender que a escola possui recursos - humanos e didáticos - para consolidar ações que promovam a leitura, mediando atividades que impactem significativamente nas experiências entre o leitor e o texto.

Os primeiros encontros na biblioteca escolar apontam, também, que a prática da leitura/escuta do texto literário desencadeia novas atividades de letramento. Durante a aplicação do projeto, muitas atividades se configuraram como ótimas oportunidades de ampliar o letramento dos estudantes. Algumas delas:

a) Consulta ao dicionário;

b) Pesquisa sobre a história de vida dos escritores lidos

(biografia/documentário);

c) Produção textual oral e escrita (textualização de crônicas);

d) Visualização de filmes/vídeos adaptadas de obras lidas;

e) Contato com variados gêneros e suportes;

f) Aprendizagem mediada pelas tecnologias da comunicação e da informação;

g) Atividades em grupos;

h) Ilustrações de obras lidas através de desenhos, entre outras.

Nesse sentido, o presente projeto de intervenção se mostra como uma ação válida no desenvolvimento dos múltiplos letramentos, ampliando consideravelmente as interações com os textos que circulam socialmente. Das 
muitas atividades desenvolvidas a partir da leitura em voz alta, o nosso ponto de partida e de chegada está situado no processo de textualização do gênero crônica.

A crônica literária foi selecionada por se aproximar do gênero que os estudantes sinalizaram ter mais contato, conto de fadas (figura 1). Os dois gêneros em discussão, segundo Dolz \& Schneuwly (2004) pertencem ao agrupamento de gênero da ordem do NARRAR, portanto se organizam em torno de uma mesma sequência narrativa. Podemos reproduzir uma sequência narrativa da seguinte forma:

Figura 4 - Sequência narrativa adaptada de Guimarães (2006)

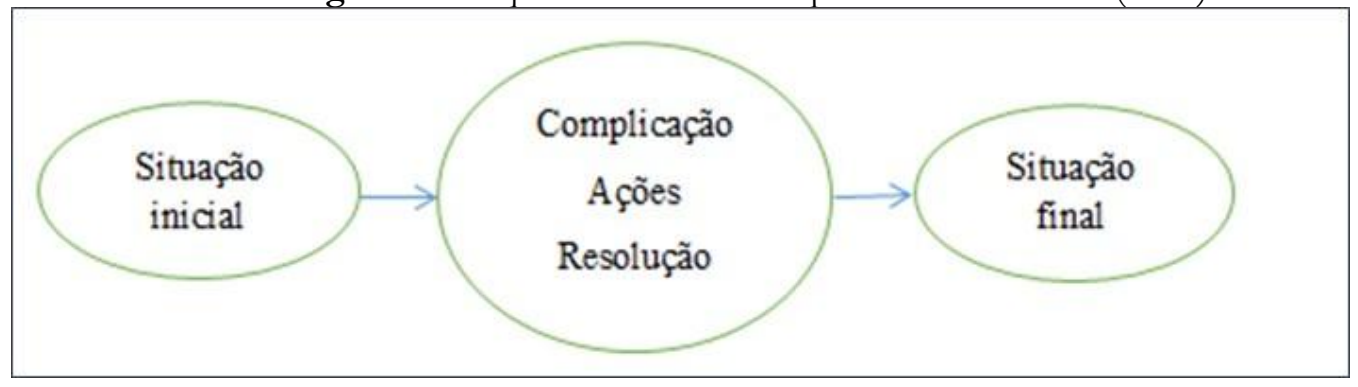

A partir da seleção do gênero, os estudantes tiveram contato com a crônica e realizaram sua primeira produção textual com base nos seus conhecimentos prévios, sem uma orientação mais sistemática, a não ser que o texto escrito deveria apresentar uma situação vivida por eles ou por pessoas conhecidas. Analisando a primeira escrita, foi possível perceber que dos textos escritos pelos 22 estudantes, 9 traziam de forma marcante expressões que indicam a situação inicial e final dos contos de fada: "Era uma vez...", “E viveram felizes para sempre."

Figura 5 - Primeira produção de uma crônica (Situação inicial)

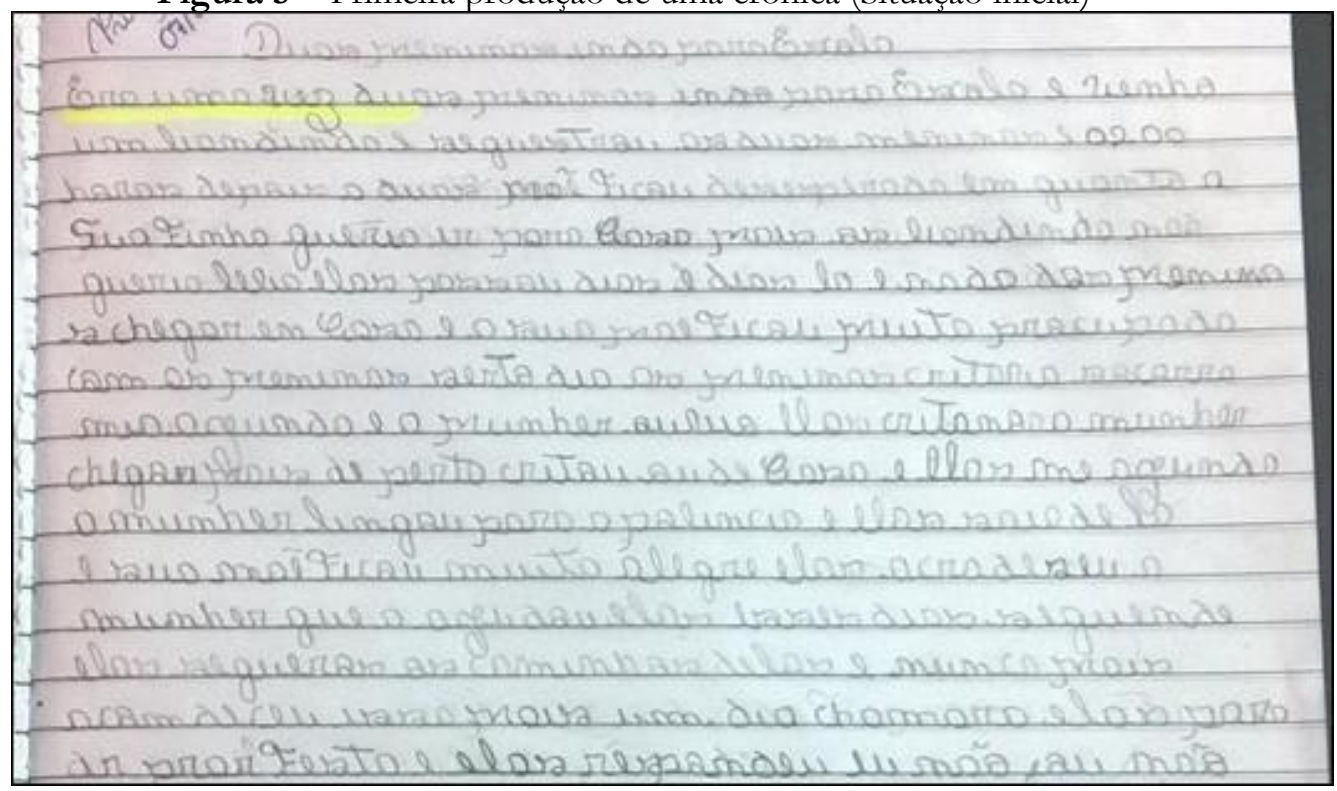


Figura 6 - Primeira produção de uma crônica (Situação final)

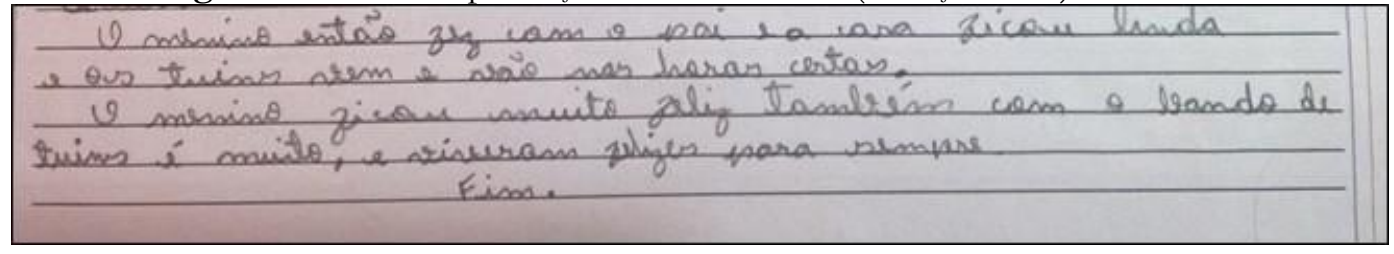

A partir daí, os módulos que compuseram as oficinas se constituíram como material de contato e reconhecimento do gênero crônica e tiveram a seguinte configuração:

\section{OFICINA DOS SABERES}

\section{Módulo 1 - Cotidiano}

O que são crônicas?

Apresentação de uma seleção crônicas e a partir dela, observação de suas principais características. Neste módulo, as crianças tiveram contato com livros compostos por crônicas, conheceram seus autores e o contexto de produção: crônicas Vou-me embora desta casa e A educação em pés descalços (SCLIAR, 2000, 1998); entre outras.

\section{Módulo 2-O que será?}

Lendo crônicas na biblioteca da escola: leitura em voz alta

Neste módulo foi escolhida a crônica O menino e o tuim (BRAGA, 1986) para a realização de sua leitura em voz alta. O texto foi lido por partes e as crianças criavam expectativas sobre os acontecimentos relacionados aos elementos sequenciais da narrativa (Figura 4) a cada leitura.

\section{Módulo 3 - Produzindo um final para a história}

Completando o final da crônica: produção escrita

Ao final da leitura da terceira parte da crônica $O$ menino e o tuim (Braga), foi proposto aos estudantes que produzissem o final da história. Percebeu-se nessa produção, ainda, um aspecto pertencente ao conto de fadas: o final feliz marcado pela expressão "E viveram felizes para sempre".

\section{Módulo 4 - E não viveram felizes para sempre!}

Finais inesperados: escrevendo coletivamente uma história do cotidiano

Aqui, os estudantes socializaram o final da história produzido por eles. Dos 22 finais produzidos pelas crianças, apenas 3 trazem um final contrário ao dos contos de fadas, sinalizando outras possibilidades de finalizar uma narrativa. Após a leitura realizada pelos estudantes dos finais da crônica por eles produzidos, foi lido, em voz alta, o final original da história O menino e o tuim (BRAGA, 1986) que 
não traz o elemento "mágico" dos contos de fadas, elemento este que colabora para um final feliz. O desfecho da crônica lida em voz alta é contrário às expectativas das crianças o que permitiu uma reflexão sobre o repertório de leitura. As crianças se dão conta que conhecem muito sobre finais felizes e muito pouco, ainda, sobre finais que se aproximam da realidade.

Nesse ponto, inicia-se a progressão da leitura trazendo um dado novo na construção do conhecimento sobre leitura: nem toda história tem final feliz. Neste ponto da intervenção foi proposto que as crianças produzissem coletivamente uma crônica com uma temática do cotidiano deles.

\section{Módulo 5 - Eu sou o escritor}

Histórias da minha vida: escrevendo uma crônica engraçada

A partir de conhecimentos relacionados ao gênero estudado, crônica literária, as crianças puderam, empreender a primeira escrita individual. A proposição tomou como base as crônicas engraçadas que foram lidas durante o projeto e que tiveram como tema a vida dos escritores ou de fatos do cotidiano observados por esses autores. Assim, cada criança pode escrever sobre fatos engraçados ocorridos no seu cotidiano.

Figura 9 - Produção final da crônica

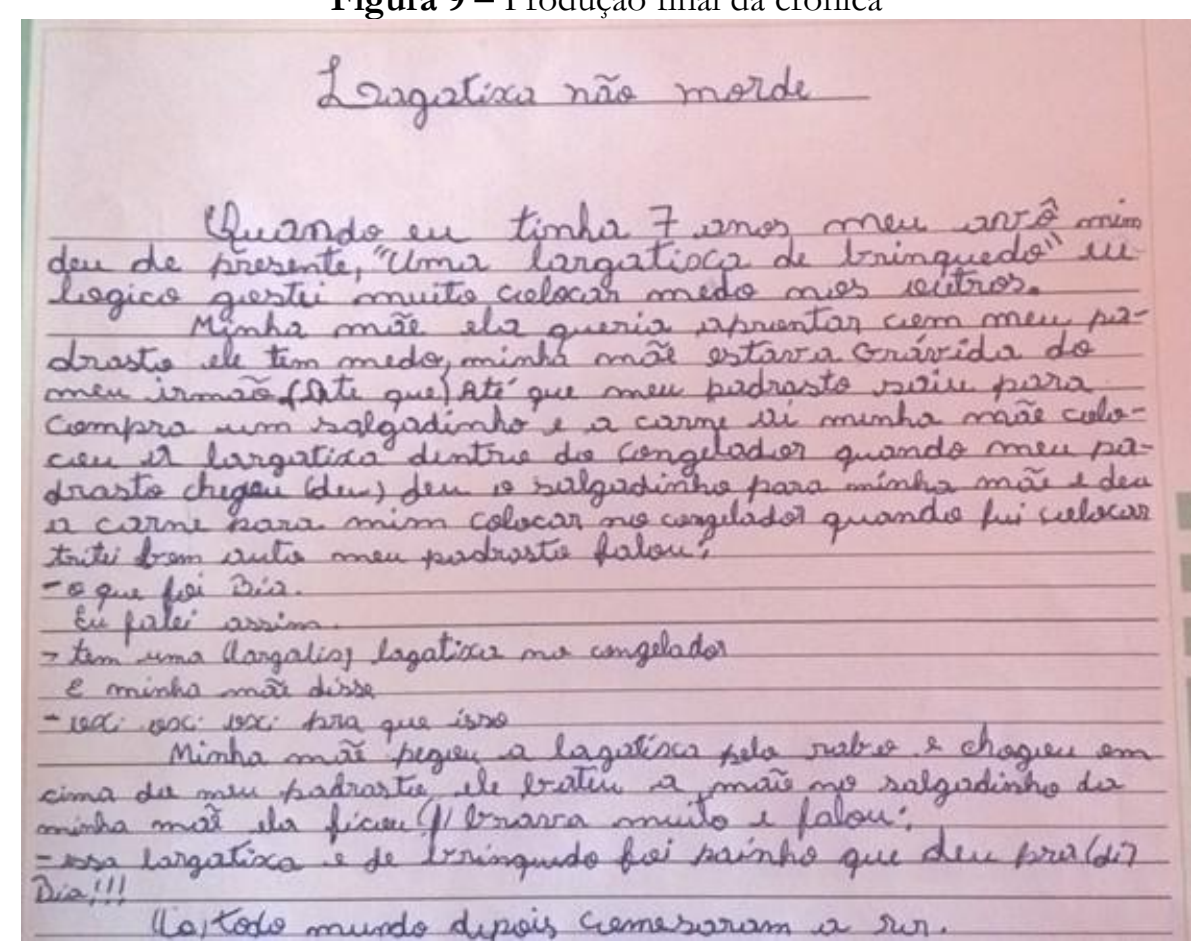

Em relação à primeira produção, que não teve uma orientação específica sobre o gênero, a produção final, realizada nessa etapa, apresenta um distanciamento dos contos de fada trazendo uma característica presente desse gênero: a marca pessoal de escrita. 


\section{CONSIDERAÇÕES}

Os temas que envolvem leitura e letramentos têm suscitado muitas discussões em âmbito nacional devido ao desempenho não satisfatório dos estudantes em indicadores nacionais e internacionais. Buscando compreender essa realidade, as atividades propostas nesse projeto visaram conhecer o perfil leitor do estudante ao final do primeiro ciclo do Ensino Fundamental.

Os resultados parciais têm motivado a reflexão sobre o papel das sequências didáticas nas práticas de ensino de língua portuguesa entre docentes. A aplicação das atividades, aqui propostas, apontam importantes contribuições para a ampliação das capacidades de linguagem. A análise dos textos produzidos pelos estudantes mostrou, inicialmente, que as dificuldades relacionadas às questões da temática da crônica se resolveram à medida que os estudantes foram mobilizados a realizar a adequação textual; ler e escrever requerem tempo e planejamento e; para se tornarem leitores muitos estudantes precisam ter exemplos e o professor pode ser uma excelente referência.

Portanto, é preciso considerar que o papel do professor é fundamental no que diz respeito à organização das práticas de ensino da língua pela via das sequências didáticas que têm como objeto de ensino os gêneros textuais. Investir nesta direção pode contribuir para responder a alguns questionamentos que nos fazemos na caminhada docente: Os estudantes podem falar, ler e escrever melhor? É possível motivá-los, mesmo na era da tecnologia, a produzir textos orais e escritos no espaço escolar? A escola ainda pode encantar os estudantes? As análises desta intervenção apontam que sim.

Além disso, pensar o tempo e eleger espaços para a leitura se torna urgente, não apenas como forma de instrumentalizar os indivíduos para as demandas sociais, mas também para possibilitar o cruzamento de histórias de vida, ajudando a ressignificar a realidade ao redor.

\section{REFERÊNCIAS}

BALDI, Elizabeth. Leitura nas séries iniciais: uma proposta para a formação de leitores de literatura. Porto Alegre: Editora Projeto, 2009.

BRAGA, Rubem. O menino e o tuim. São Paulo: Quinteto Editorial, 1986.

BRASIL. Parâmetros Curriculares Nacionais: Língua Portuguesa. Brasília-DF, 1998.

DOLZ, Joaquim; Schneuwly, B; e colaboradores. Gêneros orais e escritos na escola. Tradução e organização de Roxane Rojo e Glaís Sales Cordeiro. Campinas/SP: Mercado das Letras, 2004. 
FREIRE, Paulo. A importância do ato de ler: em três artigos que se completam. São Paulo: Autores Associados/Cortez Editora, 1989.

FUNARI, Raquel dos Santos. A maior biblioteca do mundo: curiosidades que não acabam mais sobre a Biblioteca de Alexandria. In: Revista Ciência Hoje das Crianças. ISSN 0103-2054, n. 234, maio de 2012, Ano 25.

GUIMARÃES, Ana Maria de Mattos. Construindo propostas de didatização de gêneros: desafios e possibilidades. In: Linguagem em (Dis)curso - LemD. Tubarão, v. 6, n. 3. P. $347-374$, set./dez. 2006.

JOUVE, Vincent. A leitura. São Paulo: Editora Unesp, 2002.

MORAES, Fabiano; VALADARES, Eduardo; AMORIM, Marcela Mendonça. Alfabetizar letrando na biblioteca escolar. São Paulo: Cortez, 2013

SCLIAR, Moacyr. Vou-me embora desta casa. In: Para gostar de ler. Volume 18 crônicas. Um país chamado infância. São Paulo: Editora Ática, 2000.

- A educaşão em pés descalços. Disponível em http://www1.folha.uol.com.br/fsp/cotidian/ff25059807.htm

SOLÉ, Isabel. Estratégias de leitura. Porto Alegre: Artmed, 1998.

VIGOTSKY, Lev Semenovich. A formação social da mente: o desenvolvimento dos processos psicológicos superiores. São Paulo: Martins Fontes, 2007. 